J. Dairy Sci. 95:5597-5603

http://dx.doi.org/10.3168/jds.2012-5714

(C) American Dairy Science Association ${ }^{\circledR}, 2012$.

\title{
Inactivation of Escherichia coli in milk and concentrated milk using pulsed-light treatment
}

\author{
B. M. Miller, A. Sauer, and C. I. Moraru ${ }^{1}$ \\ Department of Food Science, Cornell University, Stocking Hall, Ithaca, NY 14853
}

\section{ABSTRACT}

Pulsed light (PL) treatment has been viewed as an alternative to thermal treatments for the inactivation of pathogenic and spoilage microorganisms in recent years. The objectives of this study were to quantify the effectiveness of PL on inactivating Escherichia coli in cow milk and to evaluate the effect of total solids and fat content on inactivation. Samples of reconstituted milk with variable total solids levels $(9.8,25$, and $45 \%)$ and commercial cow milk with different fat contents (skim milk, $2 \%$ fat, and whole milk) were inoculated with nonpathogenic E. coli ATCC 25922 at a concentration of $10^{7} \mathrm{cfu} / \mathrm{mL}$. One milliliter of the inoculated sample was placed in a thin layer in a glass chamber and exposed to PL doses of up to $14.9 \mathrm{~J} / \mathrm{cm}^{2}$, both in static mode and turbulent mode. Survivors were quantified using standard plate counting. All experiments were performed in triplicate. Pulsed light treatment of the concentrated milks of 25 and $45 \%$ solids content resulted in reductions of less than $1 \mathrm{log}$, even in turbulent mode, whereas for the milk with $9.8 \%$ solids content, reduction levels of $2.5 \mathrm{log}$ cfu were obtained after treatment with $8.4 \mathrm{~J} / \mathrm{cm}^{2}$ in turbulent mode. In the skim milk, a $3.4 \log$ cfu reduction at $14.9 \mathrm{~J} / \mathrm{cm}^{2}$ was obtained and a plateau of the inactivation curve typical of PL treatment was not achieved. Under the same conditions, both $2 \%$ and whole milk attained inactivation levels greater than $2.5 \log \mathrm{cfu}$. These data indicate that PL is effective for the inactivation of $E$. coli in milk, but has limited effectiveness for microbial inactivation in concentrated milk, due to the absorption of light by the milk solids and shielding of the bacteria in the concentrated substrates. Milk fat also diminishes the effectiveness of PL to some extent, due to light-scattering effects.

Key words: pulsed light, Escherichia coli, concentrated milk, fat

Received May 10, 2012.

Accepted June 22, 2012

${ }^{1}$ Corresponding author: cim24@cornell.edu

\section{INTRODUCTION}

Foodborne illness outbreaks caused by the consumption of contaminated foods continue to be a major concern in the United States and worldwide (Scallan et al., 2011). Dairy products still contribute to outbreak statistics, despite the highly regulated and widely implemented pasteurization of milk. Milk must be pasteurized before interstate sale in the United States, according to the Pasteurized Milk Ordinance of the US Food and Drug Administration (FDA; US FDA, 2009). Nonetheless, illnesses due to the consumption of milk still occur. Eighty-three fluid milk-borne outbreaks were reported between 1990 and 2006 in the United States, resulting in 3,621 illnesses. Of these outbreaks, $44.6 \%$ were associated with the consumption of pasteurized milk (Newkirk et al., 2011). A large listeriosis outbreak was reported in Germany in 2006 to 2007, in which 189 patients were affected by eating a commercial cheese made from pasteurized milk contaminated with Listeria monocytogenes (Koch et al., 2010). In one of the largest dairy-borne outbreaks in Japan, milk powder contaminated with Staphylococcus aureus enterotoxin A affected 13,420 people (Asao et al., 2003).

Although HTST treatment of milk is known to cause minimal undesirable changes in sensory properties and quality, continued pressure exists from consumers for non-heat-treated foods, including milk (Zink, 1997). As pointed out by Oliver et al., (2009), some consumers believe that non-heat-treated milk has better taste, nutrition, and health benefits, however unsubstantiated these claims may be. Pulsed-light $(\mathbf{P L})$ treatment has emerged in recent years as a viable alternative to heat treatment for the inactivation of microorganisms in foods, on food packaging, on food contact surfaces, and even in waste streams (Woodling and Moraru, 2007; Moraru and Uesugi, 2009; Sauer and Moraru, 2009; Harrington, 2011). Some interest also exists in the dairy industry to explore light-based treatments (UV and PL) as an alternative to heat treatment (Nieburg, 2010).

Pulsed-light treatment was approved by the FDA for the treatment of foods and food surfaces, provided that the radiation source is a xenon flashlamp that emits 
broadband-spectrum radiation in the wavelength range of 200 to $1,100 \mathrm{~nm}$, with a pulse duration of less than 2 $\mathrm{ms}$, and a total treatment not exceeding $12 \mathrm{~J} / \mathrm{cm}^{2}$ (US FDA, 1996). Although the exact mechanism of inactivation has not been fully elucidated, it is generally agreed that most of the inactivation effect comes from the UV range [wavelength $(\lambda)<300 \mathrm{~nm}$ ] of the PL spectrum (Rowan et al., 1999; Woodling and Moraru, 2007). It has been suggested that PL is more effective than continuous UV treatment due to higher penetration depth and emission power, with high peak power of pulses, although this is still debated (Oms-Oliu et al., 2010). Most likely, inactivation occurs through dimer formation and helix distortion of microbial DNA (Rowan et al., 1999). A recent study found that, in addition to the DNA damage induced by PL, inactivation was also achieved through a photothermal and photophysical effect, which caused cell wall and membrane rupture, leading to leakage of the cytoplasm, and ultimately to cell death (Cheigh et al., 2012).

Pulsed-light and UV treatments have been shown to be effective at reducing the bacterial load in liquid dairy foods in previous work. Krishnamurthy et al. (2007) found reduction of up to $7.26 \mathrm{log}$ cfu of Staph. aureus in raw milk at 2 passes in a PL unit at a distance of $11 \mathrm{~cm}$ from the lamp. Matak et al. (2005) reported a $5.45 \mathrm{log}$ cfu reduction of $L$. monocytogenes in raw goat milk when exposed to $16.9 \mathrm{~mJ}$ of UV light $/ \mathrm{cm}^{2}$ in a flow-through system. Reinemann et al. (2006) observed a 3 - $\log$ reduction in total viable bacterial count in raw cow milk using a circulating UV treatment system at a dose of $15 \mathrm{~kJ} / \mathrm{L}$. Variations in treatment effectiveness between these studies can be mostly attributed to the substrate, as absorption, reflection, and scattering of light by the substrate can reduce the effectiveness of the light-based treatment. No systematic information is available, however, on how the effectiveness of PL treatment in cow milk is affected by milk components. Therefore, the main objectives of this study were to evaluate the effectiveness of PL treatment for the inactivation of Escherichia coli in milk and to evaluate the effect of fat and TS content on inactivation.

\section{MATERIALS AND METHODS}

\section{Substrates}

To evaluate the effect of solids on inactivation, commercially available nonfat instant milk powder was reconstituted to the desired solids content. Three different levels of TS were chosen for the reconstituted milk: 9.8 (package instructions to produce skim milk), 25, and $45 \%$. The appropriate amount of powdered milk was weighed and added to autoclaved distilled water to produce the desired levels of TS. The reconstituted samples were then stored in a refrigerator at $4^{\circ} \mathrm{C}$ for up to $22 \mathrm{~h}$ to allow full hydration. Prior to the PL treatment, the samples were removed from the refrigerator and immediately placed in an ice bath to maintain the sample temperature at approximately $4^{\circ} \mathrm{C}$.

For the evaluation of fat percentage on PL effectiveness, commercially available cow skim milk, $2 \%$ milk, and whole milk (3.25\% fat) were used. The milk samples were stored at $4^{\circ} \mathrm{C}$ for less than $48 \mathrm{~h}$ until use and then transferred to an ice bath at approximately $4^{\circ} \mathrm{C}$ immediately before treatment.

\section{Composition of the Milk Powder}

The milk powder used for substrate preparation was analyzed at Dairy One Inc. (Ithaca, NY) for fat, total nitrogen $(\mathrm{TN})$, and lactose content, using ether extraction (AOAC International, 2000; method 989.05; 33.2.26), Kjeldahl (AOAC International, 2000; method 991.20; 33.2.11), and enzymatic analysis (AOAC International, 2000; method $984.15 ; 33.2 .24$ ), respectively. The TS content of the powders was measured by forcedair oven drying (AOAC International, 2000; method $990.20 ; 33.2 .44)$. The milk powder had an average of $0.5 \mathrm{~g}$ of fat, $34.8 \mathrm{~g}$ of total protein, $96.1 \% \mathrm{TS}, 7.8 \mathrm{~g}$ of ash, and $53.1 \mathrm{~g}$ of lactose.

\section{Challenge Organism and Inoculum Preparation}

The challenge microorganism used in this work was nonpathogenic E. coli ATCC 25922 in the stationary growth stage. This microorganism was previously proven to be an appropriate surrogate organism for the pathogenic E. coli O157:H7 for continuous UV light treatment (Quintero-Ramos et al., 2004). Escherichia coli O157:H7 is not frequently a cause of foodborne outbreaks in dairy products, with only 1 of 38 raw milkassociated outbreak reported to the Centers for Disease Control and Prevention (Atlanta, GA) between 1973 and 1992, and 6 of 46 unpasteurized milk outbreaks from 1990 to 2006 being attributed to E. coli O157:H7 contamination (Headrick et al., 1998; Newkirk et al., 2011). Earlier work demonstrated that E. coli ATCC 25922 was an appropriate surrogate organism for E. coli O157:H7 in terms of response to PL treatment (Sauer and Moraru, 2009). Therefore, this strain was used in the current study as a model for studying the resistance of gram-negative microorganisms to PL inactivation in milk substrates.

Escherichia coli ATCC 25922 was maintained on Trypticase soy agar (TSA; Becton Dickinson, Sparks, $\mathrm{MD})$ at $4^{\circ} \mathrm{C}$. Prior to the PL treatments, a single colony was transferred onto a TSA plate and incubated for 22 
$\pm 2 \mathrm{~h}$ at $37 \pm 1^{\circ} \mathrm{C}$. A single colony was then transferred into Trypticase soy broth (TSB; Becton Dickinson) and incubated at $37 \pm 1^{\circ} \mathrm{C}$ for $20 \pm 2 \mathrm{~h}$, under shaking (at $230 \mathrm{rpm}$ ). An aliquot of $1 \mathrm{~mL}$ of inoculum was transferred into $9 \mathrm{~mL}$ of milk substrate, resulting in a starting population $\left(\mathbf{N}_{0}\right)$ of approximately $10^{7} \mathrm{cfu} / \mathrm{mL}$.

\section{PL Treatments}

One-milliliter volumes of the inoculated liquid milk substrates were placed in sterile, transparent Lab-Tek II Chamber Slide 1 well slides (Nalge Nunc International, Naperville, IL) with dimensions of $23.2 \times 53.3$ $\times 11.0 \mathrm{~mm}$. The bottom of the chamber was made of glass, and the side walls were made of polystyrene. Previous work has shown that substrate geometry is a very important factor for the effectiveness and uniformity of PL treatment, and that fluence decays proportionally to the second power of distance from the light source (Hsu and Moraru, 2011). Because the thickness of the liquid layer is critical for liquid substrates, , a constant thickness of the liquid layer was maintained in the current study. Specifically, $1 \mathrm{~mL}$ of liquid substrate was used, which resulted in a thickness of $1.3 \mathrm{~mm}$.

Pulsed-light treatments were performed using a RS3000C SteriPulse system (Xenon Corp., Woburn, MA). The system consists of a controller unit and a treatment chamber that houses a Xenon flash lamp. To generate turbulence during the shaking treatments, an MS 3 basic orbital shaker (IKA Works Inc., Wilmington, NC) was placed in the center of the PL treatment unit atop a stainless steel shelf, at a distance of $55.9 \mathrm{~mm}$ (2.2 in) under the lamp. The shaker was completely wrapped in aluminum foil to prevent the change of the light path inside the PL unit during treatment. The chamber slides were kept in place using a universal attachment of the shaker. For the treatments performed under turbulence, the shaker was used at a speed of 3,000 rpm. Static treatments were performed in the same manner, with the exception that the shaker was not powered on during these treatments.

Inoculated reconstituted milk and cow milk samples were exposed to treatment for 3 to 21 pulses of light, at a fluence of $0.71 \mathrm{~J} / \mathrm{cm}^{2}$, which resulted in total energy doses of 2.14 to $14.85 \mathrm{~J} / \mathrm{cm}^{2}$, respectively. All PL treatments were performed in triplicate.

\section{PL Fluence Measurements}

The dose of PL treatments, (fluence, expressed in $\mathrm{J} / \mathrm{cm}^{2}$ ) was quantified for all treatments. Measurements of fluence were taken using a pyroelectric head (PE25BBH-DIF) with a Nova II display (Ophir Optronics Inc., Wilmington, MA). The pyroelectric head was placed centrally atop a stainless steel shelf at a height of $55.9 \mathrm{~mm}$ (2.2 in) underneath the focal point of the Xenon lamp. A stainless steel aperture was used to cover the top surface, leaving a $1-\mathrm{cm}^{2}$ circular opening exposed centrally on the detector surface. For the measurements, a pulse width setting of $1.0 \mathrm{~ms}$ was used, along with a wavelength setting of $<0.3 \mathrm{~nm}$. Fluence measurements were performed in triplicate, with pauses of at least $60 \mathrm{~s}$ between measurements to prevent overheating of the pyroelectric head.

\section{Enumeration of Survivors}

Following PL treatment, the treated 1-mL sample was transferred into $7 \mathrm{~mL}$ of Butterfield's phosphate buffer (BPB) and the glass chamber was rinsed twice with $1 \mathrm{~mL}$ each of BPB, adding the rinse BPB to the treated inoculum. This yielded a volume of $10 \mathrm{~mL}$ of recovery liquid. The recovery liquid was serially diluted in $\mathrm{BPB}$, after which $100-\mu \mathrm{L}$ volumes were spread plated in duplicate on both TSA and MacConkey agar (Becton Dickinson), and incubated for $22 \pm 2 \mathrm{~h}$ at $37 \pm$ $2^{\circ} \mathrm{C}$. For the cow milk samples, the recovery liquid was produced and plated in the same manner. Survivors $(\mathrm{N})$ were then enumerated using the standard plate counting method. Because similar counts were found on both TSA and MacConkey agar (selective media for E. coli), only counts determined on TSA will be reported in this paper. Levels of microbial reduction were calculated as $\log \left(\mathrm{N} / \mathrm{N}_{0}\right)$, and inactivation curves were drawn by plotting reduction against fluence.

\section{Statistical Analysis}

For each treatment, the mean and standard deviation of survivor ratios were calculated. Analysis of variance was used to determine significant differences at $P<$ 0.05, using JMP 8.0 (SAS Institute Inc., Cary, NC).

\section{RESULTS AND DISCUSSION}

\section{Effect of TS Levels on Microbial Reduction by PL Treatment}

The level of reduction of E. coli ATCC 25922 by PL was correlated with the level of fluence used in the treatment. At the lowest fluence of $2.14 \mathrm{~J} / \mathrm{cm}^{2}$, reductions (means $\pm \mathrm{SD}$ ) of $0.21 \pm 0.03,0.13 \pm 0.05$, and $0.03 \pm 0.30 \mathrm{log}$ cfu were found, for 9.8, 25, and $45 \%$ TS, respectively. When operating at a fluence of 8.41 $\mathrm{J} / \mathrm{cm}^{2}$, inactivation of E. coli ATCC 25922 in the $9.8 \%$ TS sample reached a slightly higher reduction level $(0.41 \pm 0.04 \log \mathrm{cfu}$; Figure 1). As the concentration of TS increased to 25 and $45 \%$, the reduction levels after 


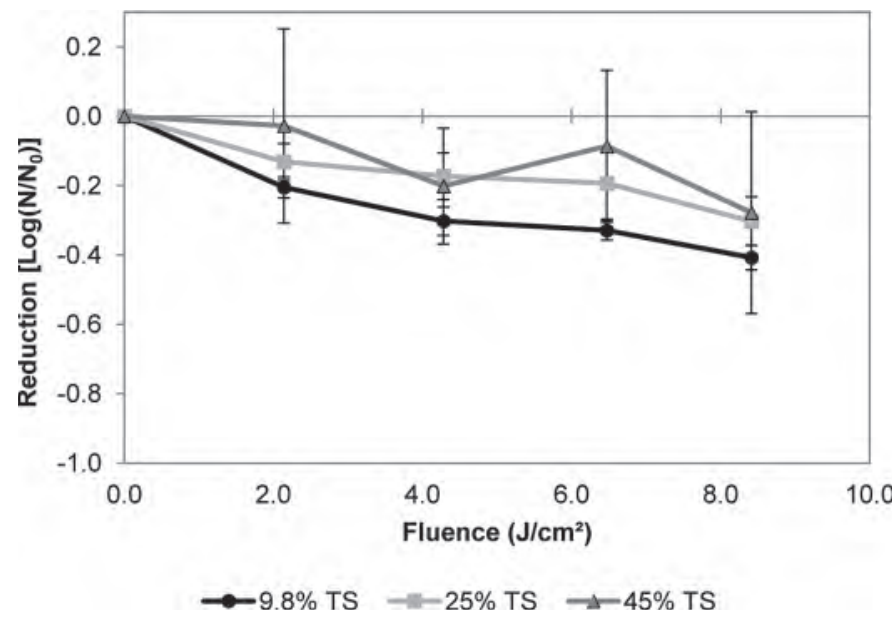

Figure 1. Inactivation of Escherichia coli in concentrated milks with 3 different TS contents by pulsed-light (PL) treatment in static mode. Plotted are mean $(\mathrm{n}=3)$ values $\pm 1 \mathrm{SD} . \mathrm{N}=$ number of survivors; $\mathrm{N}_{0}=$ number in starting population.

treatment with $8.41 \mathrm{~J} / \mathrm{cm}^{2}$ were found to be $0.30 \pm$ $0.07 \log$ cfu and $0.28 \pm 0.29 \log$ cfu, respectively. No statistical difference between the different substrates was observed. These levels of inactivation are extremely low, almost negligible from a microbiological point of view, indicating that $\mathrm{PL}$ treatment of concentrated milks in static mode is rather ineffective.

Use of turbulence enhanced the inactivation of $E$. coli by PL treatment. In this study, turbulence was achieved by using a variable-speed orbital shaker inside the PL unit, to mimic turbulence created in a commercial flowthrough treatment system. At a fluence level of $8.41 \mathrm{~J} /$ $\mathrm{cm}^{2}$, a $2.05 \pm 0.11 \mathrm{log}$ cfu reduction (means $\pm \mathrm{SD}$ ) was achieved for the reconstituted milk with 9.8\% TS (Figure 2). At the same treatment dose, significantly lower reduction levels were observed for the higher TS content milks, with reductions in E. coli of $0.62 \pm 0.07 \log$ cfu and $0.45 \pm 0.40 \log$ cfu for 25 and $45 \%$ TS, respectively. The difference between the reduction levels for the $2 \mathrm{TS}$ concentrations was statistically insignificant. Whereas the $9.8 \%$ TS reconstituted milk reached inactivation levels similar to that of HTST pasteurization (Grant et al., 1996), the 2 samples with larger percentages of TS failed to reach this level of reduction. This can mostly be attributed to the solids in the substrate reflecting and absorbing the light, which causes lower light penetration and, thus, lower levels of PL inactivation.

\section{Effect of Fat Content on PL Inactivation of E. coli in Milk}

For the treatment of fluid milk samples of varying percent fat, fluence levels of up to $14.85 \mathrm{~J} / \mathrm{cm}^{2}$ were investigated, which was above the FDA-mandated limit of $12 \mathrm{~J} / \mathrm{cm}^{2}$ (US FDA, 1996). For the milk samples, increasing fluence increased the reduction levels of $E$. coli ATCC 25922 by PL, until a plateau was reached; a plateau was not observed for the turbulent treatments.

In the static treatments, inactivation levels (means $\pm \mathrm{SD}$ ) of up to $0.35 \pm 0.08 \mathrm{log}$ cfu and a plateau of the inactivation curve were reached, with no statistically significant differences between skim, $2 \%$ fat, and whole milks (Figure 3). By comparison, Palgan et al. (2011) found a maximum reduction of $0.99 \log$ for $E$. coli in full-fat milk at a distance of $2.5 \mathrm{~cm}$ from the light source in static mode at a fluence of $14 \mathrm{~J} / \mathrm{cm}^{2}$, which was higher than in the current study.

Pulsed-light treatment effectiveness for these samples increased when the treatments were performed under shaking. Under turbulent conditions, the inactivation levels for E. coli in skim milk reached $3.36 \pm 0.21 \mathrm{log}$ at $14.85 \mathrm{~J} / \mathrm{cm}^{2}$, and a plateau was not achieved (Figure 4). The effect of turbulence decreased from skim milk to the samples with higher fat content ; for $2 \%$ fat and whole milk samples, inactivation levels of $2.89 \pm 0.06$ $\log$ and $2.94 \pm 0.35 \mathrm{log}$ at a fluence of $14.85 \mathrm{~J} / \mathrm{cm}^{2}$ were attained, respectively, (Figure 4). No statistical difference existed between inactivation levels for $2 \%$ fat milk and whole milk under turbulent conditions. This data suggests that PL treatment effectiveness was hindered by the presence of milk fat, most likely due to scattering of the incident light by the fat globules. However, it should be noted that inactivation levels comparable to HTST pasteurization (over $2 \log \mathrm{cfu}$ ) were attained for all fat levels at about $12 \mathrm{~J} / \mathrm{cm}^{2}$, which is the maximum level of fluence accepted by the FDA (US FDA, 1996).

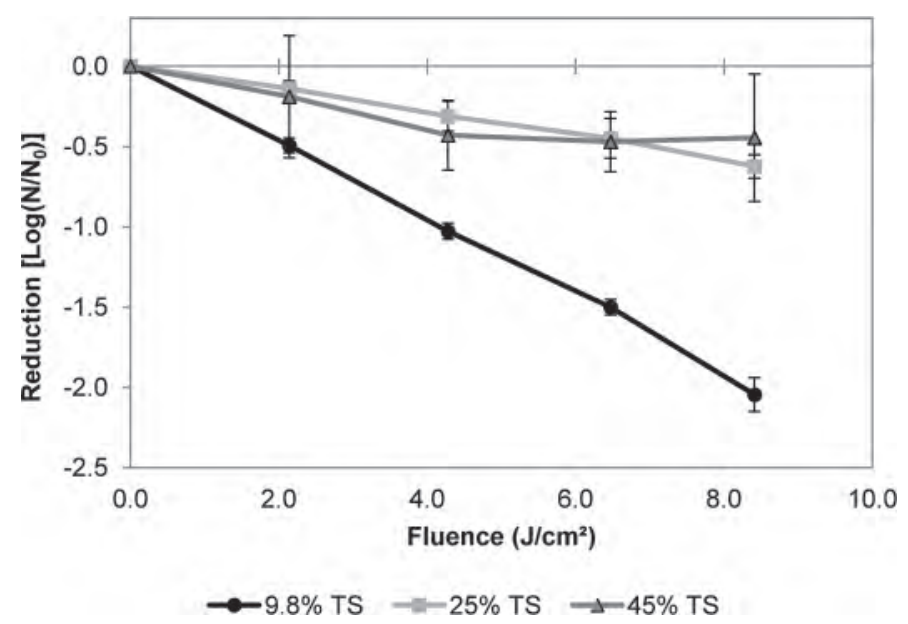

Figure 2. Inactivation of Escherichia coli in concentrated milks with 3 different TS contents by pulsed-light (PL) treatment, under shaking. Plotted are mean $(\mathrm{n}=3)$ values $\pm 1 \mathrm{SD} . \mathrm{N}=$ number of survivors; $\mathrm{N}_{0}=$ number in starting population. 


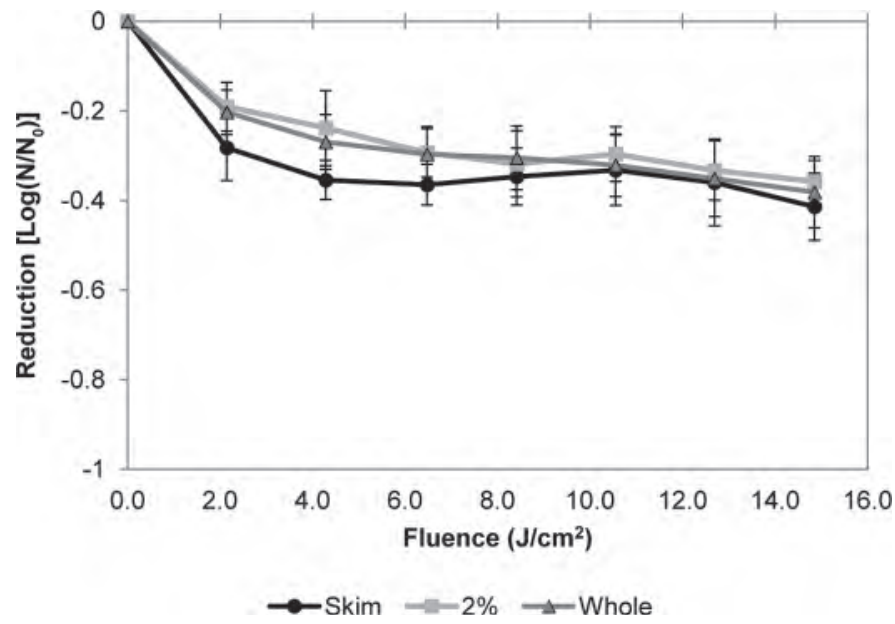

Figure 3. Inactivation of Escherichia coli in cow milk with varying fat levels by pulsed-light (PL) treatment in static mode. Plotted are mean $(\mathrm{n}=3)$ values $\pm 1 \mathrm{SD}$. $\mathrm{N}=$ number of survivors; $\mathrm{N}_{0}=$ number in starting population.

\section{Inactivation Kinetics for E. coli ATCC 25922}

When designing microbial inactivation treatments, it is helpful to be able to do theoretical calculations and predict the treatment dose necessary to achieve a desired level of inactivation. In thermal treatment, first-order kinetics are typically used to do process calculations (i.e., to determine what treatment dose is required to achieve a certain inactivation level). However, it has been shown that the use of first-order inactivation kinetics is not appropriate for PL inactivation (Uesugi et al., 2007). This is confirmed by the results obtained in the current study, as the inactivation curves for E. coli had both concave and linear shapes (Figures 1-4).

The Weibull model has been used before to successfully model microbial inactivation by PL (Uesugi et al., 2007; Sauer and Moraru, 2009). The Weibull model is a nonmechanistic model that uses a power function to describe the change of survivor ratio as a function of the intensity of the treatment. For PL treatment, the Weibull function has the general form (Uesugi et al., 2007)

$$
\log \left(\mathrm{N} / \mathrm{N}_{0}\right)=-\alpha \cdot \mathrm{F}^{\beta}
$$

where $\mathrm{N}$ is the number of survivors after PL treatment (cfu); $\mathrm{N}_{0}$ is the number of $E$. coli before PL treatment (cfu); $\alpha$ is the scale parameter; $\beta$ is the shape factor, which describes the shape of the curve; and $\mathrm{F}$ is the PL fluence $\left(\mathrm{J} / \mathrm{cm}^{2}\right)$.

To obtain Weibull parameters, Equation 1 was linearized, the logarithm of $\log \left(\mathrm{N} / \mathrm{N}_{0}\right)$ was plotted against the logarithm of fluence, and the regression equation $\mathrm{y}=\beta \cdot \mathrm{x}+n$ was used to obtain the regression parameters $\beta$ and $n$, where $n=\log (\alpha)$. For $E$. coli ATCC 25922 in $9.8 \%$ TS concentrated milk, the Weibull equation took the form

$$
\log \left(\mathrm{N} / \mathrm{N}_{0}\right)=0.48 \cdot \mathrm{F}^{0.14} .
$$

The calculated shape and scale parameters $(\beta$ and $\alpha$, respectively) for the PL inactivation of E. coli ATCC 25922 in the other substrates are presented in Table 1. As shown by the coefficient of determination values in Table 1, the Weibull model was able to accurately calculate PL inactivation for most conditions, with a few exceptions.

Although the current study was concerned with microbial inactivation effects of PL, it is important to make some comments regarding the effects of this treatment on the quality and sensory properties of milk treated by PL. To date, only a few sensory studies of milk treated by other light-based methods have been published. Krishnamurthy (2006) conducted a sensory evaluation of pasteurized milk that was treated by PL. A consumer panel of 29 evaluated samples for overall acceptability, and it was found that the acceptability decreased about 4 points on a 9-point hedonic scale between the control and PL-treated milk, although the level of treatment was not indicated (Krishnamurthy, 2006). Matak et al. (2007) explored the sensory changes (odor) of goat milk when exposed to $15.8 \pm 1.6 \mathrm{~mJ} /$ $\mathrm{cm}^{2}$ of continuous UV irradiation. A significant negative difference was found in the odor of the milk treated

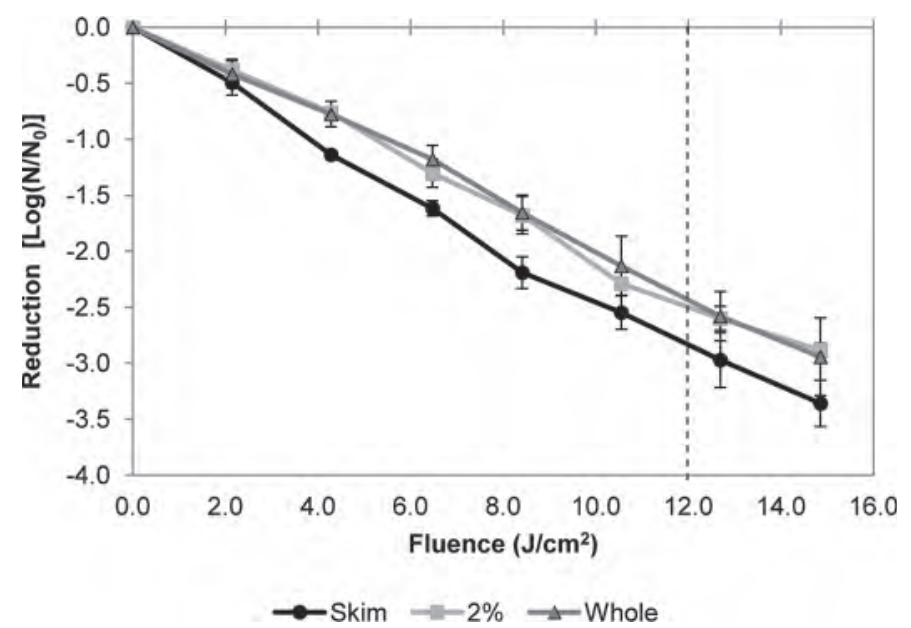

Figure 4. Inactivation of Escherichia coli in cows' milk with varying fat levels by pulsed-light (PL) treatment, under turbulence. Plotted are mean $(\mathrm{n}=3)$ values $\pm 1 \mathrm{SD}$. The dotted line indicates the maximum fluence of $12 \mathrm{~J} / \mathrm{cm}^{2}$ allowed for treatment of foods, as mandated by the Food and Drug Administration (US FDA, 1996). N $=$ number of survivors; $\mathrm{N}_{0}=$ number in starting population. 
Table 1. Weibull parameters for the inactivation of Escherichia coli ATCC 25922 in concentrated milk and cow milk substrates

\begin{tabular}{|c|c|c|c|c|c|c|}
\hline Substrate type & Substrate & Mode & $\begin{array}{l}\text { No. of data } \\
\text { points }\end{array}$ & $\begin{array}{c}\text { Shape } \\
\text { parameter } \beta\end{array}$ & $\begin{array}{c}\text { Scale } \\
\text { parameter } \alpha\end{array}$ & $\begin{array}{l}\text { Goodness } \\
\text { of fit }\left(\mathrm{R}^{2}\right)\end{array}$ \\
\hline \multirow[t]{5}{*}{ Concentrated milk } & \multirow[t]{2}{*}{$9.8 \% \mathrm{TS}$} & Turbulent & 5 & 1.04 & 0.22 & 1.00 \\
\hline & & Static & 5 & 0.48 & 0.14 & 0.97 \\
\hline & $25 \% \mathrm{TS}$ & Static & 5 & 0.54 & 0.08 & 0.84 \\
\hline & \multirow[t]{2}{*}{$45 \% \mathrm{TS}$} & Turbulent & 5 & 0.67 & 0.13 & 0.83 \\
\hline & & Static & 5 & 1.41 & 0.01 & 0.65 \\
\hline \multirow{4}{*}{ Cow milk } & \multirow[t]{2}{*}{$2 \%$} & Turbulent & 8 & 1.08 & 0.17 & 1.00 \\
\hline & & Static & 8 & 0.31 & 0.15 & 0.94 \\
\hline & \multirow[t]{2}{*}{ Whole } & Turbulent & 8 & 1.03 & 0.18 & 1.00 \\
\hline & & Static & 8 & 0.30 & 0.17 & 0.97 \\
\hline
\end{tabular}

with 12 passes of UV irradiation $\left(15.6-\mathrm{mJ} / \mathrm{cm}^{2}\right.$ dose) compared with the raw goat milk (Matak et al., 2007). On the other hand, Elmnasser et al. (2008) found that only minimal chemical changes in terms of lipids and proteins were induced in milk by PL treatment. A systematic study of the effect of PL treatments that are effective for microbial inactivation on the overall quality of treated milk products will be required, and this will be the subject of a subsequent study.

\section{CONCLUSIONS}

Inactivation of $E$. coli in highly concentrated milks by PL treatment does not present an effective alternative to conventional pasteurization, as illustrated by the less than 1-log reduction reached. Even with the addition of turbulence, the concentrated milk samples failed to reach sufficient levels of inactivation to be an adequate replacement of conventional pasteurization. Pulsed-light treatment could, however, be an effective alternative to pasteurization for fluid milk, based on levels of total inactivation obtained in this study (higher than 2-log reduction). Although this shows potential for the use of PL for the treatment of fluid milk, before a recommendation is made to consider PL as a viable alternative to HTST pasteurization, the effectiveness of this treatment against the pathogens of concern in milk (Mycobacterium tuberculosis and Coxiella burnetii) needs to be tested. In addition, the effect of the treatment on the chemical and sensory properties of the treatment milk also needs to be investigated.

\section{ACKNOWLEDGMENTS}

The authors thank the Cornell Presidential Scholars program (Ithaca, NY) for supporting author B. M. Miller to conduct this research. We also thank Randy Worobo's laboratory (Cornell University, Ithaca, NY) for providing the used E. coli strain and Lillian Hsu (Cornell University) for her technical assistance.

\section{REFERENCES}

AOAC International. 2000. Official Methods of Analysis of AOAC International. 17th ed. AOAC International, Arlington, VA.

Asao, T., Y. Kumeda, T. Kawai, T. Shibata, H. Oda, K. Haruki, H. Nakazawa, and S. Kozaki. 2003. An extensive outbreak of staphylococcal food poisoning due to low-fat milk in Japan: Estimation of enterotoxin A in the incriminated milk and powdered skim milk. Epidemiol. Infect. 130:33-40.

Cheigh, C.-I., M.-H. Park, M.-S. Chung, J.-K. Shin, and Y.-S. Park. 2012. Comparison of intense pulsed light- and ultraviolet (UVC)induced cell damage in Listeria monocytogenes and Escherichia coli O157:H7. Food Contr. 25:654-659.

Elmnasser, N., M. Dalgalarrondo, N. Orange, A. Barkhrouf, T. Heartlé, M. Federighi, and J.-M. Chobert. 2008. Effect of pulsedlight treatment on milk proteins and lipids. J. Agric. Food Chem. 56:1984-1991

Grant, I. R., H. J. Ball, S. D. Neill, and M. T. Rowe. 1996. Inactivation of Mycobacterium paratuberculosis in cows' milk at pasteurization temperatures. Appl. Environ. Microbiol. 62:631-636.

Harrington, R. 2011. Pulsed light poised for wider industry adoption. Accessed Jun. 24, 2011. http://www.foodproductiondaily.com/ Quality-Safety/Pulsed-light-poised-for-wider-industry-adoption.

Headrick, M. L., S. Korangy, N. H. Bean, F. J. Angulo, S. F. Altekruse, M. E. Potter, and K. C. Klontz. 1998. The epidemiology of raw milk-associated foodborne disease outbreaks reported in the United States, 1973 through 1992. Am. J. Public Health 88:1219-1221.

Hsu, L., and C. I. Moraru. 2011. Quantifying and mapping the spatial distribution of fluence inside a pulsed light treatment chamber and various liquid substrates. J. Food Eng. 103:84-91.

Koch, J., R. Dworak, R. Prager, B. Becker, S. Brockmann, A. Wicke, H. Wichmann-Schauer, H. Hof, D. Werber, and K. Stark. 2010. Large listeriosis outbreak linked to cheese made from pasteurized milk, Germany, 2006-2007. Foodborne Pathog. Dis. 7:1581-1584.

Krishnamurthy, K. 2006. Decontamination of milk and water by pulsed UV-light and infrared heating. PhD Thesis. Pennsylvania State Univ., University Park.

Krishnamurthy, K., A. Demirci, and J. M. Irudayaraj. 2007. Inactivation of Staphylococcus aureus in milk using flow-through pulsed UV-light treatment system. J. Food Sci. 72:M233-M239.

Matak, K. E., J. J. Churey, R. W. Worobo, S. S. Sumner, E. Hovingh, C. R. Hackney, and M. D. Pierson. 2005. Efficacy of UV light for the reduction of Listeria monocytogenes in goat's milk. J. Food Prot. 68:2212-2216.

Matak, K. E., S. S. Sumner, S. E. Duncan, E. Hovingh, R. W. Worobo, C. R. Hackney, and M. D. Pierson. 2007. Effects of ultraviolet irra- 
diation on chemical and sensory properties of goat milk. J. Dairy Sci. 90:3178-3186.

Moraru, C. I., and A. R. Uesugi. 2009. Pulsed-light treatment: Principles and applications. Pages 235-265 in Ultraviolet Light in Food Technology: Principles and Applications. T. N. Koutchma, L. J. Forney, and C. I. Moraru, ed. CRC Press, New York, NY.

Newkirk, R., C. Hedberg, and J. Bender. 2011. Establishing a milkborne disease outbreak profile: Potential food defense implications. Foodborne Pathog. Dis. 8:433-437.

Nieburg, O. 2010. UK Dairy sector eyes energy saving pasteurisation alternative to extend milk shelf-life. Dairy Reporter: July 2, 2010. Accessed Feb. 29, 2012. http://www.dairyreporter.com/Processing-Packaging/UK-dairy-sector-eyes-energy-saving-pasteurisationalternative-to-extend-milk-shelf-life.

Oliver, S. P., K. J. Boor, S. C. Murphy, and S. E. Murinda. 2009. Food safety hazards associated with consumption of raw milk. Foodborne Pathog. Dis. 6:793-806.

Oms-Oliu, G., O. Martin-Belloso, and R. Soliva-Fortuny. 2010. Pulsed light treatments for food preservation. A review. Food Bioprocess Technol. 3:13-23.

Palgan, I., I. M. Caminiti, A. Muñoz, F. Noci, P. Whyte, D. J. Morgan, D. A. Cronin, and J. G. Lyng. 2011. Effectiveness of high intensity light pulses (HILP) treatments for the control of Escherichia coli and Listeria innocua in apple juice, orange juice and milk. Food Microbiol. 28:14-20.

Quintero-Ramos, A., J. J. Churey, P. Hartman, J. Barnard, and R. W. Worobo. 2004. Modeling of Escherichia coli inactivation by UV irradiation at different $\mathrm{pH}$ values in apple cider. J. Food Prot. 67:1153-1156.

Reinemann, D. J., P. Gouws, T. Cilliers, K. Houck, and J. R. Bishop. 2006. New methods for UV treatment of milk for improved food safety and product quality. Paper no. 066088 in Proc. ASAE Annual Meeting. American Society of Agricultural and Biological Engineers, St Joseph, MI.

Rowan, N. J., S. J. MacGregor, J. G. Anderson, R. A. Fouracre, L. McIlvaney, and O. Farish. 1999. Pulsed-light inactivation of foodrelated microorganisms. Appl. Environ. Microbiol. 65:1312-1315.

Sauer, A., and C. I. Moraru. 2009. Inactivation of Escherichia coli ATCC 25922 and Escherichia coli O157:H7 in apple juice and apple cider, using pulsed light treatment. J. Food Prot. 72:937-944.

Scallan, E., R. M. Hoekstra, F. J. Angulo, R. V. Tauxe, M.-A. Widdowson, S. L. Roy, J. L. Jones, and P. M. Griffin. 2011. Foodborne illness acquired in the United States-Major pathogens. Emerg. Infect. Dis. 17:7-15.

Uesugi, A. R., S. E. Woodling, and C. I. Moraru. 2007. Inactivation kinetics and factors of variability in the pulsed light treatment of Listeria innocua cells. J. Food Prot. 70:2518-2525.

US FDA (Food and Drug Administration). 1996. Title 21-Food and Drugs, Chapter I-Food and Drug Administration, Department of Health and Human Services, Part 179-Irradiation in the Production, Processing and Handling of Food. US FDA, Silver Spring, MD.

US FDA (Food and Drug Administration). 2009. Grade "A" Pasteurized Milk Ordinance. 2009 Revision. Accessed Oct. 28, 2011. http://www.fda.gov/downloads/Food/FoodSafety/Product-SpecificInformation/MilkSafety/NationalConferenceonInterstateMilkShipmentsNCIMSModelDocuments/UCM209789.pdf.

Woodling, S. E., and C. I. Moraru. 2007. Effect of spectral range in surface inactivation of Listeria innocua using broad-spectrum pulsed light. J. Food Prot. 70:909-916.

Zink, D. L. 1997. The impact of consumer demands and trends on food processing. Emerg. Infect. Dis. 3:467-469. 